\title{
Effect of nanostructure on the supercapacitor performance of activated carbon xerogels obtained from hydrothermally carbonized glucose-graphene oxide hybrids
}

M. Enterría ${ }^{1 *}$, F.J. Martín-Jimeno ${ }^{2}$, F. Suárez-García ${ }^{2}$, J.I. Paredes ${ }^{2}$, M.F.R. Pereira ${ }^{1}$, J.I. Martins $^{3,4}$, A. Martínez-Alonso ${ }^{2}$, J. M. D. Tascón ${ }^{2}$, J.L. Figueiredo ${ }^{1}$

1 Laboratório de Processos de Separação e Reacção - Laboratório de Catálise e Materiais (LSRE-LCM), Departamento de Engenharia Química, Faculdade de Engenharia, Universidade do Porto. R. Dr Roberto Frias s/n, 4200-465 Porto, Portugal.

${ }^{2}$ Instituto Nacional del Carbón, INCAR-CSIC, Apartado 73, 33080, Oviedo, Spain

${ }^{3}$ Departamento de Engenharia Química, Faculdade de Engenharia, Universidade do Porto.R. Dr Roberto Frias s/n, 4200-465, Porto, Portugal.

${ }^{4}$ Universidade do Minho, LAB2PT- Laboratório de Paisagens, Património e Território.

*Corresponding author. Tel.: +351225081400. Email: menterria@,fe.up.pt (Marina Enterría) 


\begin{abstract}
Activated carbon xerogels with a cellular morphology were obtained from hydrothermally carbonized glucose-graphene oxide (GO) hybrids and tested as supercapacitor electrodes. The effect of the chemical activation (using $\mathrm{KOH}$ ) on the nanometer-scale morphology, local structure, porous texture and surface chemistry of the resulting carbon materials was investigated and correlated with their electrochemical behaviour. The electrochemical performance of the activated xerogels was studied in a three-electrode cell using $1 \mathrm{M} \mathrm{H}_{2} \mathrm{SO}_{4}$ as the electrolyte. The results underlined the relevant role played by the xerogel nanomorphology; more specifically, xerogels with cellular structures exhibiting well-connected, continuous and very thin $(\sim 5-15 \mathrm{~nm})$ carbon walls (prepared with lower amounts of activating agent) favored ionic diffusion and electronic conduction compared to materials with broken, thicker walls (obtained from higher amounts of activating agent). The effect of nanomorphology and local structure was also made apparent when the xerogels were used as actual supercapacitor electrodes. Particularly, a symmetric capacitor assembled from a carbon xerogel with very thin walls and relatively high graphitic character delivered a much higher specific capacitance than that of a commercial activated carbon ( 223 vs $153 \mathrm{~F} \mathrm{~g}^{-1}$ at $100 \mathrm{~mA} \mathrm{~g}^{-1}$ ) as well as a significantly improved retention of capacitance at high current densities.
\end{abstract}




\section{Introduction}

Beyond conventional activated carbons, the discovery of graphene has provided new horizons in the energy field [1]. Arising from its particular two-dimensional structure, graphene has superior electrical conductivity, highly accessible surface area and excellent chemical and mechanical properties. Supercapacitors (SCs) are devices that store energy by means of electrostatic charge separation as opposed to the electrochemical reactions in conventional batteries [2]. While the latter present serious power limitations and rarely provide immediate response to energy peak demands, SCs can store energy when it is produced in excess for fast releasing when necessary (high power density). Unfortunately, they cannot supply high capacitances or high energy densities as compared with batteries [3]. Commercial activated carbons are by far the most widely used material for SC electrodes; nevertheless, their capacitances are typically limited to $40-160 \mathrm{~F} \mathrm{~g}^{-1}$ [4] in aqueous electrolyte. The intrinsic principle of charge storage in SCs consists of electrostatic adsorption of electrolyte ions on the electrode surface [2] and, consequently, the surface area is the main factor influencing the capacitance. However, there are other factors that strongly contribute to the capacitance of carbon-based electrodes. For example, the presence of functional groups on the carbon surface can enhance the electrode capacitance by fast reversible faradaic reactions between the electrode surface and the electrolyte (pseudocapacitance) [5] or by increasing the electrode wettability [6]. On the other hand, a suitable nanostructure enhancing both the electrolyte diffusion [7-9] and the electronic conduction $[6,10]$ is also expected to boost the electrochemical performance. In this context, the development of porous carbons comprising thin (nanometric) carbon walls produced by using graphene sheets or other structures as templates to afford, e.g., monolithic carbon 
gels would be highly desirable, as the thin walls would bring such advantages as enhanced kinetics for ion diffusion $[11,12]$. This type of gel material can be attained by coating the flat, non-porous conductive surface of graphene with a porous carbon layer. At present, carbon gels are most commonly prepared using highly toxic resorcinol/formaldehyde mixtures as carbon precursors [13, 14] and, consequently, a large amount of work has been dedicated to find alternative carbon precursors. For instance, biomass-derived products (pure carbohydrates and lignocellulosic substances) are considered as a potential carbon sources to produce valuable porous carbon materials [15], since they are a renewable resource available in high quantities. However, the utilization of pure carbohydrates (i.e., glucose, sucrose, fructose, starch, etc) for sol-gel synthesis has met with limited success, due to their poor reactivity in highly diluted media. The as-obtained carbon gels suffer from poor mechanical/chemical resistance and low carbon yields after carbonization. Recently, it has been found that more robust polymeric structures can be obtained by using certain condensation/polymerization promoters, including graphene oxide (GO) nanosheets. GO is an oxygen-rich material produced by the oxidative exfoliation of graphite. The acidic sites on GO have been shown to promote dehydration/condensation reactions of carbohydrates and other organic precursors whilst providing a scaffold that supports the growth of carbon xerogels, for example by hydrothermal means [16, 17]. Hydrothermal carbonization (HTC) is a mild process $\left(180-250^{\circ} \mathrm{C}\right)$ that has been largely demonstrated to promote the condensation, polymerization, and aromatization of saccharides in solution [18]. In fact, activated carbon xerogels produced by HTC of glucose-GO mixtures have been very recently reported [16]. These carbon materials are a priori good candidates for the development of a new family of carbon-based SCs since porous carbon-GO hybrids have already demonstrate to be good candidates for energy storage 
applications, such as supercapacitors [19] or lithium-sulfur batteries [20, 21]. Therefore, in the present work we investigate the potential of these novel GO-based carbon xerogels towards their use as SCs and demonstrate the dominant role played by the xerogel nanostructure on their performance at real implementation conditions (high current densities).

\section{Experimental}

\subsection{Synthesis of the activated carbon xerogels}

The activated carbon xerogels were prepared by a slight modification of a recently reported procedure that makes use of GO sheets as morphology-directing agents in the HTC of glucose, affording hydrothermal carbon xerogels that are then chemically activated with $\mathrm{KOH}$ [16]. GO sheets (lateral size: $\sim 0.2-1 \mu \mathrm{m}$ ) in aqueous colloidal dispersion were obtained through oxidation (Hummers method) and subsequent sonication-induced exfoliation of natural graphite powder (Sigma Aldrich) following a protocol described elsewhere [22]. To obtain the hydrothermal carbon xerogels, glucose ( $2 \mathrm{~g}$ ) was dissolved in $20 \mathrm{~mL}$ of aqueous $\mathrm{GO}$ suspension (GO concentration: $2 \mathrm{mg} \mathrm{mL}-$ ${ }^{1}$ ), and the resulting mixture was transferred to a Teflon-lined autoclave $(50 \mathrm{~mL}$ in capacity) and heated at $200{ }^{\circ} \mathrm{C}$ for $16 \mathrm{~h}$. The resulting wet hydrogels were thoroughly rinsed with deionized water, immersed consecutively in three volumes of neat acetone (30 $\mathrm{mL}, 15 \mathrm{~min}$ each time) and then allowed to dry under ambient conditions. We note that this washing procedure is significantly different (i.e., much more extensive) compared to that followed in a previous paper describing the synthesis of this type of material. This extensive washing afforded the extraction of a considerable amount of non-polar, low molecular weight compounds from the hydrogel (the originally transparent acetone turned brown due to this extraction). As noted below, the porous 
texture of the activated carbon xerogels derived from this enhanced washing process was much less dependent on the activation parameters, which allowed us to investigate the effects of nanostructure on the supercapacitor performance of these materials. After the washing and drying steps, the resulting hydrothermal carbon xerogels were chemically activated with $\mathrm{KOH}$. To this end, a given volume of an aqueous $\mathrm{KOH}$ solution of known concentration was drop-casted onto, and absorbed by, the xerogel, which was then allowed to dry under ambient conditions. Two KOH/hydrothermal carbon weight ratios were used, namely, 1 and 4 . These $\mathrm{KOH}$-impregnated samples were subsequently heat-treated at either 700 or $800{ }^{\circ} \mathrm{C}$ for 30 min under Ar flow (300 $\mathrm{mL} \min ^{-1}$ ) to finally afford activated carbon xerogels, which were thoroughly washed with deionized water and dried at $90{ }^{\circ} \mathrm{C}$ for $12 \mathrm{~h}$. The differently activated samples are denoted as $\mathrm{K} x \_\mathrm{T} y$, where $x$ stands for the $\mathrm{KOH} / \mathrm{hydrothermal}$ carbon weight ratio (i.e., 1 or 4) and $y$ is either 7 or 8 , which refers to the activation temperature (i.e., 700 and 800 ${ }^{\circ} \mathrm{C}$, respectively). For comparison purposes, a hydrothermal carbon was prepared using the same synthesis conditions but in absence of the GO suspension. The resulting hydrothermal carbon obtained by hydrothermal carbonization of glucose only (without GO) was activated with a $\mathrm{KOH} /$ hydrothermal carbon weight ratio of $1 / 1$ at $800{ }^{\circ} \mathrm{C}$ and was denoted as Glu_K1_T8.

\subsection{Characterization techniques}

An Autosorb-1 volumetric adsorption analyzer (Quantachrome) was used to measure $\mathrm{N}_{2}$ adsorption-desorption isotherms, at $-196^{\circ} \mathrm{C}$ in the relative pressure range of $10^{-7}-0.99$. Samples were degassed at $250^{\circ} \mathrm{C}$ overnight under vacuum. The BET surface area $\left(\mathrm{S}_{\mathrm{BET}}\right)$ was calculated according to the BET model [23] from the nitrogen isotherms in the relative pressure range of $0.01-0.15$. The micropore volume $\left[\left(\mathrm{V}_{\mathrm{DR}}\left(\mathrm{N}_{2}\right)\right]\right.$ were 
calculated by applying the Dubinin-Radushkevich (DR) method [23] in the relative pressure ranges of $10^{-6}-0.15$. The total pore volume $\left(\mathrm{V}_{\mathrm{T}}\right)$ was calculated as the amount of $\mathrm{N}_{2}$ adsorbed at the relative pressure of 0.95 . The QSDFT [23] method (slit-cylindrical pores, equilibrium) was used to obtain the pore size distributions (PSDs). Field emission scanning electron microscopy (FE-SEM) imaging of the samples was conducted with a Quanta FEG 650 microscope (FEI Company) operated at $30 \mathrm{kV}$. Raman spectra were recorded with a LabRam apparatus (Horiba Jobin-Yvon) using a $532 \mathrm{~nm}$ wavelength laser at an incident power of $0.5 \mathrm{~mW}$ to avoid damage/modification of the xerogel samples due to excessive heating. X-ray photoelectron spectroscopy (XPS) was carried out on a SPECS system under a pressure of $10^{-7} \mathrm{~Pa}$ using a non-monochromatic $\mathrm{Mg} \mathrm{K}$ $\mathrm{X}$-ray source operated at $11.81 \mathrm{kV}$ and $100 \mathrm{~W}$.

\subsection{Electrochemical measurements}

\subsubsection{Electrode preparation}

The obtained carbon xerogels were hand-milled to obtain a particle size below $100 \mu \mathrm{m} . \quad$ A carbon paste was prepared by mixing $10 \mathrm{wt} \%$ of polytetrafluoroethylene (PTFE) in absolute ethanol and $90 \mathrm{wt} \%$ of the activated xerogels. Then, 5-10 $\mathrm{mg}$ of the resulting paste was pressed into a mould (3 ton, $15 \mathrm{~s})$. The as-prepared carbon pellets $\left(0.78 \mathrm{~cm}^{2}\right)$ were sandwiched between two stainless steel meshes (w/w \%: Fe 67.77\%, 0.08\% C; 0.04\% P; 1.95\% Mn; 0.50\% $\mathrm{Si} ; 0.03 \% \mathrm{~S} ; 10.30 \% \mathrm{Ni} ; 17.65 \% \mathrm{Cr} ; 1.68 \% \mathrm{Mo}$ ) and pressed (3 ton, $15 \mathrm{~s})$. The obtained electrodes were vacuum-degassed for $4 \mathrm{~h}$ at $120^{\circ} \mathrm{C}$, soaked into the electrolyte and kept immersed into the solution during 1 day. The cell assembly process was reported in our previous work [24]. Nitrogen gas was bubbled into the electrolyte for $15 \mathrm{~min}$ prior to the measurements to remove the $\mathrm{O}_{2}$ present into 
the electrolyte solution. The electrochemical characterization was performed on a PGZ 402 Voltalab potentiostat (Radiometer Analytical) by using both three-electrode and two-electrode cell configurations

\subsubsection{Three-electrode configuration}

The electrochemical behavior of the prepared carbons was studied in a beakertype cell in $1 \mathrm{M} \mathrm{H}_{2} \mathrm{SO}_{4}$ with an $\mathrm{Ag} / \mathrm{AgCl}(\mathrm{KCl} 1 \mathrm{M})$ reference electrode. The counter electrode was prepared by sandwiching $20 \mathrm{mg}$ of Norit DCL Supra $50 \AA$ carbon paste in the stainless steel meshes. The working and counter electrodes were arranged in a stack, separated by filter paper and connected to two Pt wires as current collectors. Nitrogen gas was bubbled through the electrolyte for $15 \mathrm{~min}$ prior to the measurements to remove the $\mathrm{O}_{2}$ present in the electrolyte solution. Cyclic voltammetry $(\mathrm{CV})$ was performed in a voltage window of -0.2 to $0.6 \mathrm{~V}$ at $2 \mathrm{mV}$

$\mathrm{s}^{-1}$. The specific gravimetric capacitance $\left(\mathrm{C}, \mathrm{F} \mathrm{g} \mathrm{g}^{-1}\right)$ of a single electrode was calculated by the formula:

\section{$C=\frac{1}{2 \times m V W} \int_{V_{0}}^{V_{1}} I(V) d V \quad(1)$}

where $\mathrm{r}$ is the scan rate $\left(\mathrm{V} \mathrm{s}^{-1}\right), \mathrm{m}$ the mass of the active material within the working electrode (g), $\mathrm{Vw}$ the voltage window (i.e, $\mathrm{V}_{1}-\mathrm{V}_{0}$, measured in Volt) and $\mathrm{I}$ the current (A). Electrochemical impedance spectroscopy (EIS) was applied to the fully discharged cell at $0 \mathrm{~V}$ in the frequency region of $10 \mathrm{kHz}$ to $10 \mathrm{mHz}$ with $\mathrm{AC}$ amplitude of $10 \mathrm{mV}$.

\subsubsection{Two-electrode configuration}

Two electrodes made from a given activated carbon xerogel were used as symmetric working electrodes in a two-electrode cell. Charge-discharge (CD) experiments were conducted up to $0.8 \mathrm{~V}$ and different current intensities (100-3000 mA 
$\left.\mathrm{g}^{-1}\right)$. The specific gravimetric capacitance $\left(\mathrm{F} \mathrm{g}^{-1}\right)$ of a single electrode was calculated by the formula:

$C=\frac{2 I \Delta t_{d}}{m \Delta V_{d}^{2}} \quad 2$

where $\mathrm{I}$ is the constant current $(\mathrm{A}), \Delta \mathrm{t}_{\mathrm{d}}$ the time of discharge to the fixed potential window (s), $\mathrm{m}$ the mass of the active material within the working electrode $(\mathrm{g})$ and $\Delta \mathrm{V}_{\mathrm{d}}$ the potential difference $(\mathrm{V})$ between the start and end of the discharge process after omitting the internal resistance (IR) drop. The long-term stability of the electrodes was studied by means of consecutive charge/discharge cycles of the cell (up to $100 \mathrm{~mA}$ during 10000 cycles).

\section{Results and discussion}

3.1. Morphology, structure, texture and surface chemistry of the activated carbon xerogels.

The micrometer- and nanometer-scale morphology of the activated carbon xerogels prepared as described in the Experimental section was investigated by FE-SEM. In general terms, the morphological features seem to be mostly determined by the amount of $\mathrm{KOH}$ used in the chemical activation step. Figure 1a-c shows representative FE-SEM images recorded for sample K1_T8. The material activated with the same amount of $\mathrm{KOH}$ at a lower temperature (i.e., sample K1_T7) is not significantly different from what can be seen in Figure 1a-c, so the corresponding images are not shown to avoid repetition. Both xerogels exhibit a cellular or capsule-like morphology, comprising a high density of rounded voids enclosed by very thin walls. The voids are typically between $\sim 200$ and $800 \mathrm{~nm}$ in diameter (see Figure $1 \mathrm{~b}$ and c), whereas the walls are $\sim 5$ $15 \mathrm{~nm}$ thick. The xerogels are made up of ensembles of GO sheets covered by thin 
layers of hydrothermally carbonized and $\mathrm{KOH}$-activated glucose [16]. This peculiar cellular morphology has been previously demonstrated to develop during the chemical activation step, and has been interpreted to result from the generation of spherical droplets of molten $\mathrm{KOH}$ at temperatures above $360{ }^{\circ} \mathrm{C}$ that displace and squeeze the GO-hydrothermally carbonized glucose structures on the droplet surface [16]. The morphology of xerogels activated with a large amount of KOH (i.e., samples K4) is noticeably different, as exemplified in Figure 1d-f for sample K4_T8. Specifically, these samples incorporate much larger voids, typically between a few and several micrometers in diameter. Such a result could be reasonably attributed to the formation of larger droplets of molten $\mathrm{KOH}$. However, more significantly, the walls enclosing the voids are not smooth and continuous structures as in the case of the K1 samples, but are frequently broken up into loosely connected, platelet-like pieces instead (Figure 1d). Furthermore, these platelet-like fragments are considerably thicker $(\sim 40-80 \mathrm{~nm}$, see Figure 1e and f) than the smooth walls of their K1 counterparts. By contrast, if GO was excluded from the production process, the resulting activated carbons (e.g., Glu_K1_T8) were not obtained in xerogel form but rather as a loose powder. As evidenced from SEM images (not shown) and, typical for common hydrothermal carbons, this powder was made up of individual, micrometer-sized (1-2 $\mu \mathrm{m}$ in diameter) spheres. Therefore, the presence of GO sheets during the hydrothermal carbonization step was critical in achieving the peculiar nanostructures described above for the activated xerogels. 

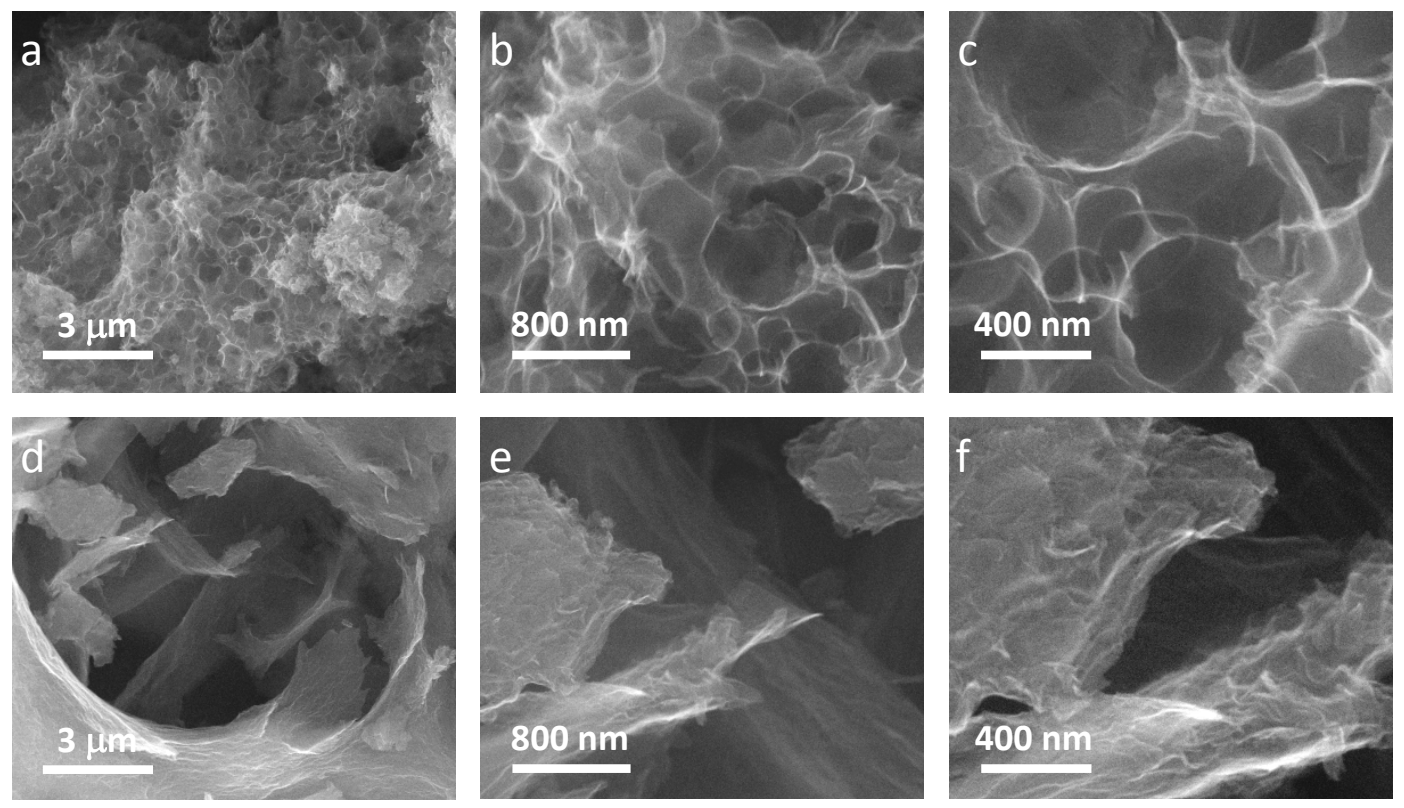

Figure 1. FE-SEM images of samples K1_T8 (a-c) and K4_T8 (d-f).

Raman spectroscopy was used to probe the structural order of the activated carbon xerogels. Figure 2 shows representative spectra recorded for the different xerogels, which are all dominated by two intense peaks located at about 1340 (D band) and 1585 (G band) $\mathrm{cm}^{-1}$, together with weak bands observed in the $2500-3300 \mathrm{~cm}^{-1}$ region (including the $2 \mathrm{D}$ band at $\sim 2680 \mathrm{~cm}^{-1}$ ). These features are known to be indicative of $\mathrm{sp}^{2}$ based carbons with a graphitic character but possessing a high density of structural imperfections $[25,26]$. The latter point was quantitatively evaluated by determining the integrated intensity ratio of the $\mathrm{D}$ and $\mathrm{G}$ bands $\left(\mathrm{I}_{\mathrm{D}} / \mathrm{I}_{\mathrm{G}}\right.$ ratio), which yielded reasonably similar values for all the samples (between 1 and 1.3). However, some small differences in the 2D band are consistently observed between samples. In particular, its intensity tends to be higher for the xerogels activated at $800{ }^{\circ} \mathrm{C}$ compared with their counterparts activated at $700{ }^{\circ} \mathrm{C}$. The emergence of an intense $2 \mathrm{D}$ band is known to be related to increased graphitic order in carbon materials [27, 28], suggesting that the structural order is somewhat better for the materials activated at the higher temperature, as could 
be expected a priori. Nevertheless, these are relatively minor differences and, overall the Raman spectroscopy data suggest that all the xerogels are structurally similar.

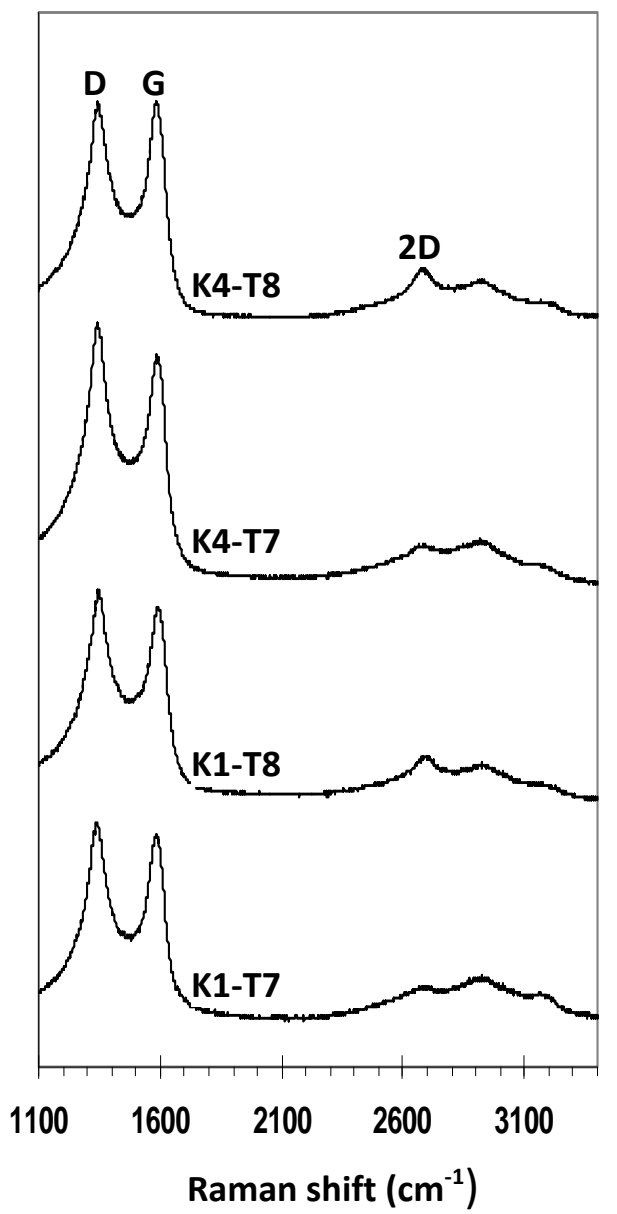

Figure 2. Raman spectra of the different activated carbon xerogels.

We note that the activated carbon xerogels investigated here comprise a GO-derived carbon framework, which possesses an $\mathrm{sp}^{2}$-based but highly defective nature, and a porous carbon derived from hydrothermally carbonized and $\mathrm{KOH}$-activated glucose, the structure of which is also expected to be based on $\mathrm{sp}^{2}$ bonding and to be highly defective. Therefore, it would be interesting to ascertain the mass fraction of these two components in the xerogels. However, determining their relative weight is far from straightforward, as analytical techniques that could be used to discriminate both 
components based on structural differences will most probably not succeed in doing so. Indeed, we used thermogravimetric analysis under air flow to see if we could detect differences in gasification temperatures that could be attributed to the either the GO- or the glucose-derived components, but only a single, continuous mass loss without individual features could be observed. However, we note that an estimate of the mass fraction of the GO-derived component in our activated xerogels could be made resorting to literature data on the $\mathrm{KOH}$ activation of reduced graphene oxide alone. Specifically, Srinivas et al [29] have provided the yield of porous carbons obtained from GO thermally reduced at $250{ }^{\circ} \mathrm{C}$ (not very different to our hydrothermal carbonization temperature) and activated with $\mathrm{KOH}$ under the same $\mathrm{KOH} /$ precursor mass ratios and temperatures used in our case. Using these data and taking into account the mass of our final activated carbon xerogels, we estimate the mass fraction of GO-derived material in our xerogels to be of the order of 50\%. Figure 3a displays the $\mathrm{N}_{2}$ adsorption/desorption isotherms recorded at $-196^{\circ} \mathrm{C}$ for the activated xerogels. The studied carbons display only slightly different isotherm shapes depending on the activation conditions: (i) K1_T7 presents a combination of types I and IV isotherm with an H4 hysteresis loop characteristic of micro-mesoporous materials with slit-shaped porosity, (ii) K1_T8 shows similar adsorption branch shape than K1_T7 but differs in the desorption branch showing a smaller hysteresis loop and (iii) Glu_K1_T8 and samples activated with higher amount on $\mathrm{KOH}$ (series $\mathrm{K} 4$ ) present type I isotherms characteristics of microporous materials. Even though all the studied materials yield similar textural features, the use of lower amounts of $\mathrm{KOH}$ (K1 samples) leads to somewhat higher specific surface areas $\left(\mathrm{S}_{\mathrm{BET}}\right.$, Table 1$)$. The PSDs of the activated xerogels analyzed by applying QSDFT to the adsorption isotherms are represented in Figure $3 \mathrm{~b}$ and the cumulative pore volumes are displayed in Table 1. Regardless of the activation 


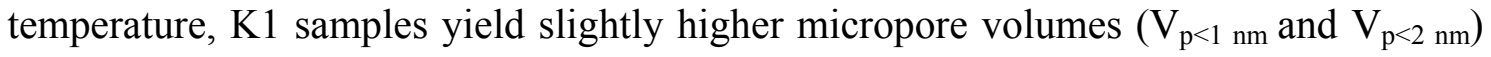
and noticeable larger mesopore volumes $\left[\left(\mathrm{V}_{\mathrm{p}}(2-50 \mathrm{~nm})\right]\right.$. Therefore, the use of a lower amount of $\mathrm{KOH}$ during the activation step can be associated in the present case to a slightly more developed microporous texture and a significantly more developed mesoporous structure (although mesopore volumes are modest at best; see Table 1).
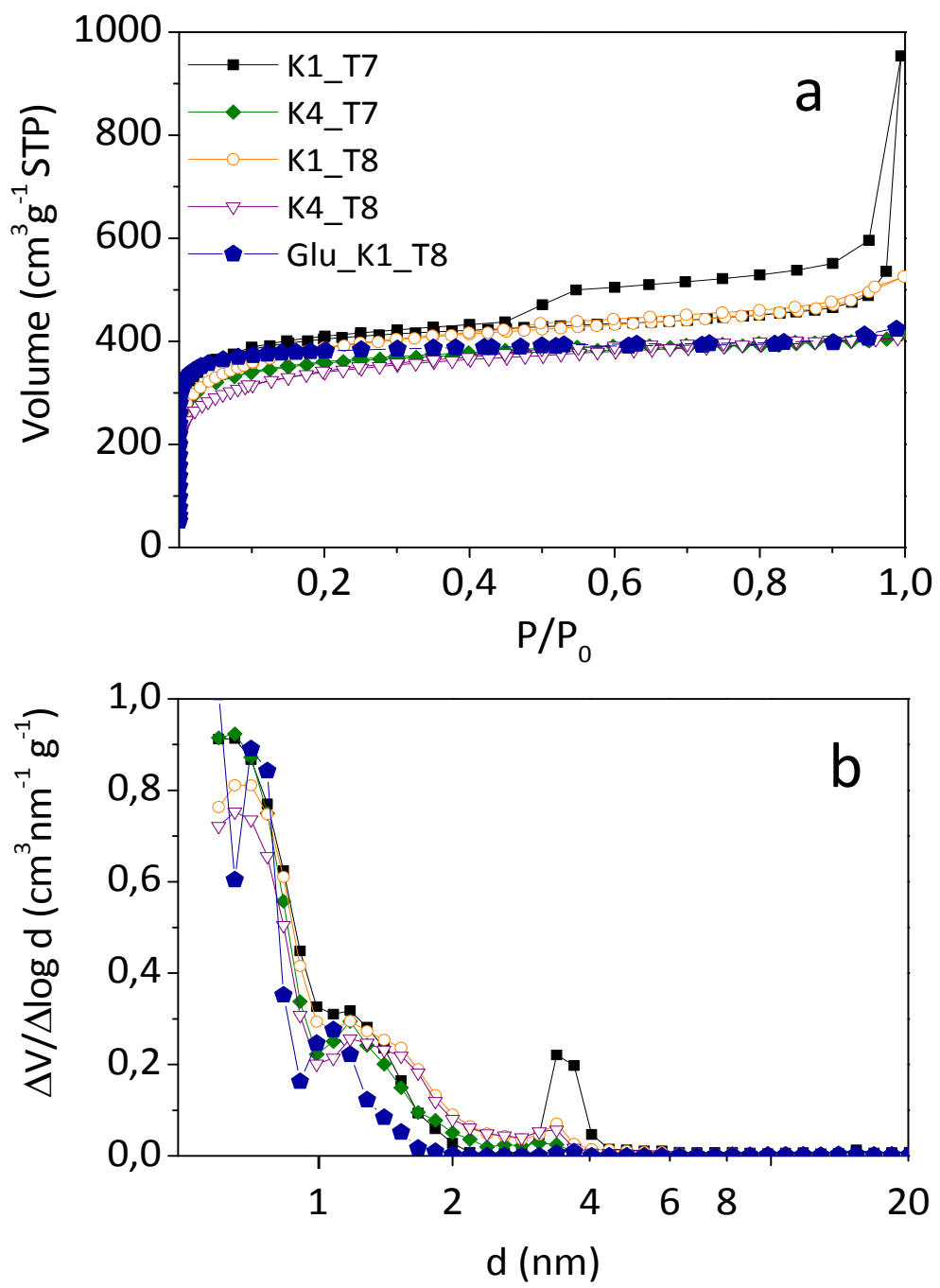

Figure 3. (a) $\mathrm{N}_{2}$ adsorption/desorption isotherms at $-196{ }^{\circ} \mathrm{C}$ for the activated carbon xerogels. (b) PSDs of the xerogels calculated from the adsorption isotherms by the QSDFT method. 
Table 1. Textural parameters obtained from $\mathrm{N}_{2}$ adsorption-desorption isotherms.

\section{QSDFT method}

\begin{tabular}{ccccccc}
\hline Sample & $\begin{array}{c}\mathbf{V}_{\mathbf{T}} \\
\left(\mathbf{c m}^{\mathbf{3}} \mathbf{g}^{-1}\right)\end{array}$ & $\begin{array}{c}\mathbf{S}_{\text {BET }} \\
\left(\mathbf{m}^{\mathbf{2}} \mathbf{g}^{-1}\right)\end{array}$ & $\begin{array}{c}\mathbf{V}_{\text {DR }} \\
\left(\mathbf{c m}^{3} \mathbf{g}^{-1}\right)\end{array}$ & $\begin{array}{c}\mathbf{V}_{\mathbf{p}}<\mathbf{1}_{\mathbf{n m}} \\
\left(\mathbf{c m}^{\mathbf{3}} \mathbf{g}^{-1}\right)\end{array}$ & $\begin{array}{c}\mathbf{V}_{\mathbf{p}}<\mathbf{2 n m} \\
\left(\mathbf{c m}^{\mathbf{3}} \mathbf{g}^{-1}\right)\end{array}$ & $\begin{array}{c}\mathbf{V}_{\mathbf{p}}(\mathbf{2 - 5 0} \mathbf{n m}) \\
\left(\mathbf{c m}^{\mathbf{3}} \mathbf{g}^{-1}\right)\end{array}$ \\
\hline K1_T7 & 0.85 & 1513 & 0.58 & 0.40 & 0.56 & 0.30 \\
K4_T7 & 0.63 & 1333 & 0.54 & 0.32 & 0.52 & 0.05 \\
K1_T8 & 0.79 & 1412 & 0.56 & 0.36 & 0.54 & 0.16 \\
K4_T8 & 0.63 & 1257 & 0.49 & 0.30 & 0.49 & 0.08 \\
Glu_K1_T8 & 0.64 & 1450 & 0.57 & 0.48 & 0.56 & 0.03 \\
\hline
\end{tabular}

The surface elemental composition and nature of the chemical groups in the carbon xerogels was investigated by XPS. As could be anticipated, only carbon and oxygen were detected. The $\mathrm{O} / \mathrm{C}$ atomic ratio of the different samples, derived from their corresponding survey spectra (not shown), are given in Table 2. Moderate values are obtained in all cases $(\mathrm{O} / \mathrm{C}$ ratios between $\sim 0.03-0.07)$, but they tend to be somewhat lower for the K4 samples. To explain this result, the following points have to be taken into account. First, the HTC process of glucose and other saccharides is known to yield carbonaceous products that are rich in oxygen and possess a complex structure consisting of small, unoxidized $\mathrm{sp}^{2}$-based aromatic domains (or oxidized only at their periphery) interspersed with furanic rings and aliphatic moieties terminated in hydroxyl and carbonyl groups $[16,18]$. Second, during the chemical activation step, $\mathrm{KOH}$ reacts with carbon atoms from the hydrothermally obtained xerogel, so that this element is removed in the form of $\mathrm{K}_{2} \mathrm{CO}_{3}$, creating porosity in the activated carbon material that is left behind [30]. Because the extent of $\mathrm{KOH}$-carbon reaction is controlled by the amount 
of $\mathrm{KOH}$ employed, this reaction is expected to be selective towards carbon atoms from disordered environments compared with unoxidized aromatic domains, and therefore to lead also to the removal of the oxygen species that are associated to such disordered carbonaceous regions. Consequently, we should expect a higher degree of removal of the oxygen rich disordered environments and so a lower $\mathrm{O} / \mathrm{C}$ ratio in the final activated carbon for samples activated with a larger amount of $\mathrm{KOH}$, as it is actually observed for the K4 xerogels compared with their K1 counterparts (see Table 2). As will be further discussed below in the light of the electrochemical characterization results, a potential consequence of the extensive removal of oxygen atoms is that the remaining aromatic domains could incorporate significant amounts of unsaturated, highly reactive edges $[31,32]$, particularly when activation is carried out at a lower temperature that is less likely to favor edge annealing (e.g., this could be the case of the xerogel activated with the larger amount of $\mathrm{KOH}$ at the lower temperature, i.e. sample K4_T7). The different types of oxygen functional groups left behind in the carbon xerogels following activation were evaluated from their high resolution C 1s core level XPS spectra, which are shown in Figure 4 (left column). The spectra could be fitted into four components (C1-C4), which are located at about $284.6 \mathrm{eV}$ (C1 component, ascribed to carbon atoms in an unoxidized $\mathrm{C}=\mathrm{C}$ graphitic environment), $285.8 \mathrm{eV}(\mathrm{C} 2$, attributed to carbon single-bonded to oxygen in, e.g., hydroxyl or ether groups), $287.0 \mathrm{eV}$ (C3, carbon atoms double-bonded to oxygen in, e.g., carbonyls) and $288.8 \mathrm{eV}$ (C4, carbon atoms from carboxylic and ester functionalities). Generally, the C 1s XPS spectrum of a pure graphitic material without heteroatoms presents an asymmetric shape. This will affect the curve fitting procedure, an asymmetric peak shape being needed for the graphitelike structure, while a gaussian peak is required for an aliphatic structure [33]. Therefore, the $\mathrm{C} 1$ component was fitted to a Doniach-Sunjic line-shape with an 
asymmetry parameter of $\alpha=0.12$ [32]. On the other hand, C2-C4 peaks were adjusted to a symmetric $80 \%$ Gaussian-Lorenzial line-shape. The relative weight of each component in the different samples is given in Table 2. The distribution of the different oxidized carbon species is relatively similar for all the activated xerogels. However, the proportion of highly oxidized carbon atoms (i.e., those in carbonyl and carboxyl/ester groups) tends to be larger for the K1 xerogels (compare the high binding energy tails of the spectra for the K1 and K4 samples in Figure 4). Concerning the high resolution O 1s core level spectra (Figure 4, right column), these were satisfactory peak-fitted to yield three components. The component centered at $530.7 \mathrm{eV}(\mathrm{O} 1)$ was ascribed to $\mathrm{C}=\mathrm{O}$ bonds in aromatic moieties, whereas that located at about $532 \mathrm{eV}$ was attributed to $\mathrm{C}=\mathrm{O}$ bonds in ester and anhydride groups, $-\mathrm{OH}$ bonds in alcohols and $\mathrm{C}-\mathrm{O}$ bonds in ethers. Finally, the component at about $533.7 \mathrm{eV}(\mathrm{O} 3)$ was associated to $\mathrm{C}-\mathrm{O}$ bonds in ethers in esters and anhydrides. It can be observed that the peaks associated to carbonyl functionalities (O1 and $\mathrm{O} 2)$ tend to be higher for $\mathrm{K} 1$ samples, which is consistent with their higher extent of oxidation as deduced from the $\mathrm{O} / \mathrm{C}$ ratios and with the $\mathrm{C} 1 \mathrm{~s}$ region analysis. 


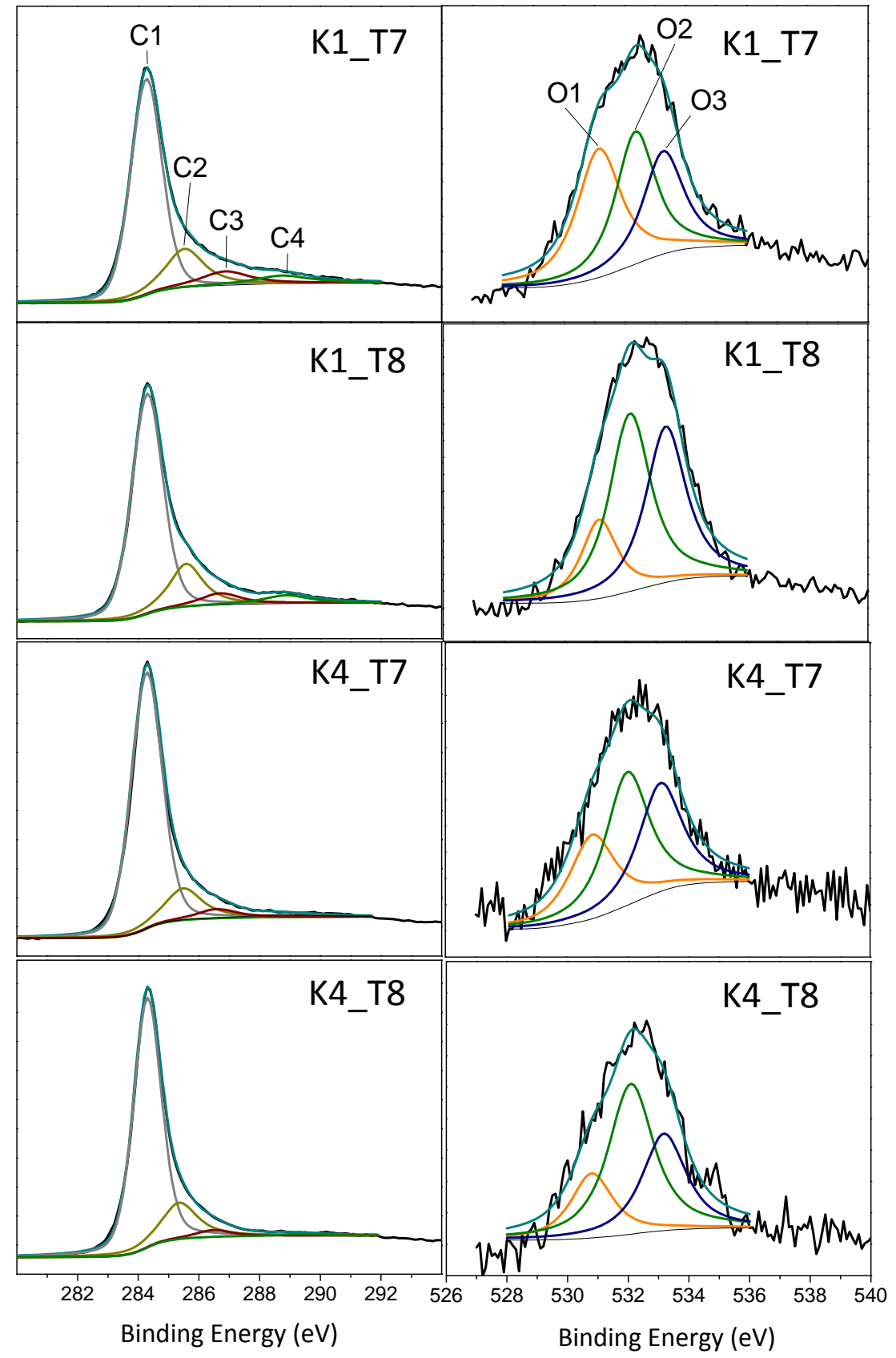

Figure 4. High resolution $\mathrm{C} 1 \mathrm{~s}$ (left column) and O1s (right column) core level spectra for the different activated carbon xerogels. The $\mathrm{C} 1 \mathrm{~s}$ spectra have been peak-fitted into four components: $\mathrm{C} 1(284.6 \mathrm{eV}), \mathrm{C} 2(285.8 \mathrm{eV}), \mathrm{C} 3(287.0 \mathrm{eV})$ and $\mathrm{C} 4(288.8 \mathrm{eV})$. The O 1s spectra have been peak-fitted into three components: $\mathrm{O} 1(530.7 \mathrm{eV}), \mathrm{O} 2(532 \mathrm{eV})$, $\mathrm{O} 3(533.7 \mathrm{eV})$. 
Table 2. $\mathrm{O} / \mathrm{C}$ atomic ratios and relative area of the different $\mathrm{C} 1 \mathrm{~s}$ and $\mathrm{O} 1 \mathrm{~s}$ components for the activated carbon xerogels as determined from the survey and high resolution XPS spectrum.

\begin{tabular}{|c|c|c|c|c|c|c|c|c|}
\hline \multirow[b]{2}{*}{ Sample } & \multirow[b]{2}{*}{$\begin{array}{c}\mathrm{O} / \mathrm{C} \\
\text { atomic } \\
\text { ratio }\end{array}$} & \multicolumn{4}{|c|}{$\begin{array}{c}\text { Relative area of } \\
\text { C } 1 \text { s component }(\%) \\
\end{array}$} & \multicolumn{3}{|c|}{$\begin{array}{c}\text { Relative area of } \\
\text { O } 1 \text { s component }(\%) \\
\end{array}$} \\
\hline & & $\begin{array}{c}\text { C1 } \\
(284.6 \\
\text { eV) } \\
\end{array}$ & $\begin{array}{c}\mathrm{C} 2 \\
(285.8 \\
\mathrm{eV}) \\
\end{array}$ & $\begin{array}{c}\text { C3 } \\
(287.0 \\
\mathrm{eV}) \\
\end{array}$ & $\begin{array}{c}\mathrm{C} 4 \\
(288.8 \\
\mathrm{eV}) \\
\end{array}$ & $\begin{array}{c}\text { O1 } \\
(530.7 \\
\text { eV) } \\
\end{array}$ & $\begin{array}{c}\text { O2 } \\
(532 \\
\mathrm{eV}) \\
\end{array}$ & $\begin{array}{c}\text { O3 } \\
(533.7 \\
\mathrm{eV}) \\
\end{array}$ \\
\hline K1_T7 & 0.066 & 86 & 7 & 4 & 2 & 45 & 21 & 34 \\
\hline K4_T7 & 0.033 & 95 & 4 & 1 & 1 & 26 & 40 & 34 \\
\hline K1_T8 & 0.068 & 87 & 8 & 2 & 3 & 20 & 52 & 28 \\
\hline K4_T8 & 0.042 & 95 & 1 & 2 & 2 & 20 & 49 & 31 \\
\hline
\end{tabular}

\subsection{Electrochemical characterization}

The electrochemical behaviour of the activated xerogels was investigated in a threeelectrode cell configuration in aqueous electrolyte $\left(1 \mathrm{M} \mathrm{H}_{2} \mathrm{SO}_{4}\right)$. Figure 5a displays the cyclic voltammograms recorded for the different xerogels at a scan rate of $2 \mathrm{mV} \mathrm{s}^{-1}$. Samples K4_T8 and Glu_K1_T8 display a square-shaped curve with almost no redox peaks, indicating mainly capacitive storage for such electrodes. By contrast, two humps for both the positive $(\sim 0.2 \mathrm{~V})$ and the negative $(\sim 0.16 \mathrm{~V})$ scan are observed for the K1_T7, K1_T8 and K4_T7 electrodes. For carbon electrodes, this type of feature is generally associated to faradaic currents arising from redox reactions involving oxygen functional groups [34-36]. Quite unexpectedly, the most intense humps are noticed for sample K4_T7, which exhibits the lowest extent of oxidation of all the investigated xerogels (Table 2). As commented above, larger amounts of $\mathrm{KOH}$ and lower activation temperatures probably lead to carbon materials possessing aromatic domains with a significant fraction of unsaturated, highly reactive edges. Therefore, in line with 
previous reports on carbon materials made up of small aromatic domains and high fractions of reactive edges, such as zeolite-templated carbons [37, 38], it was observed that the K4_T7 xerogel undergoes electrochemical oxidation when submitted to strongly acidic media. In other words, the humps observed for this sample can be ascribed to oxygen groups generated during the voltammetric measurement. This phenomenon is made evident in Figure 5c, where the evolution of the voltammetric curves with the number of cycles is compared for K4_T7 and K4_T8 samples. The area inside the curve increases for both samples throughout the measurement due to an increase in the electrode wettability. Hence, the evolution to more squared curves reveals a better capacitive performance derived from a proper infusion of the electrolyte into the electrode porosity. On the other hand, sample K4_T7 showed a notorious and progressive increment of the redox humps located around $0.2 \mathrm{~V}$, whereas sample K4_T8 displayed no changes in this potential range. The voltammetric curves seemed to stabilize after 50 cycles for both electrodes. On this basis, the faradaic activity of the investigated samples is suggested to arise both from oxygen groups originally present on the xerogels and from oxygen groups that could have originated by incipient electrooxidation during the first stages of the voltammetric measurement or even during the conditioning of the samples for the electrochemical measurement. We note that the electrodes were soaked in the electrolyte solution $\left(1 \mathrm{M} \mathrm{H}_{2} \mathrm{SO}_{4}\right)$ for one day to allow proper wetting before the electrochemical measurements were carried out. This conditioning could have induced some extent of oxidation in the sample. To test this, we soaked a certain amount of sample $\mathrm{K} 4 \_\mathrm{T} 7$ in $1 \mathrm{M} \mathrm{H}_{2} \mathrm{SO}_{4}$ for one day and examined it by XPS. We noticed that the amount of oxygen increased very significantly in this sample after $\mathrm{H}_{2} \mathrm{SO}_{4}$ soaking (the $\mathrm{O} / \mathrm{C}$ ratio increased from 0.033 to 0.22 ). Indeed, its high resolution $\mathrm{C}$ 1s spectrum revealed an increased fraction of carbon atoms in the 
285.5-287.5 eV binding energy range ( $\mathrm{C}-\mathrm{O}$ and $\mathrm{C}=\mathrm{O}$ configurations) compared with the non-soaked sample (results not shown). Furthermore, in the presence of both $\mathrm{H}_{2} \mathrm{SO}_{4}$ and a current during the cyclic voltammetry measurements, further oxidation of the sample can be expected, as suggested by Fig. 5c. These results provide additional support to the claim that (electro) chemical oxidation takes place for the K4_T7 electrodes. We also note that the extent of the contribution of intrinsic and induced oxidation to the observed faradaic currents could well depend on the sample characteristics. In fact, the faradaic activity observed for the $\mathrm{K} 1 \_\mathrm{T} 7$ and $\mathrm{K} 1 \_\mathrm{T} 8$ electrodes is more likely to arise from the quinone/hydroquinone redox pair $[2,39]$, as $\mathrm{C}=\mathrm{O}$ groups were shown to be relatively abundant in these two xerogels (see Table 2). The global specific capacitances (sum of capacitive and pseudocapacitive contributions) were calculated from the cyclic voltammograms (Fig. 5a) and are listed in Table 3. The K4_T8 xerogel exhibits a significantly lower capacitance $\left(143 \mathrm{~F} \mathrm{~g}^{-1}\right)$ compared with that of the other activated xerogels (211-239 $\left.\mathrm{F} \mathrm{g}^{-1}\right)$. This result could be expected a priori if we take into account the relatively low surface area (Table 1) and low oxygen content (Table 2) of the K4_T8 sample. Conspicuously, Glu_K1_T8 presents very similar capacitance to the analogous hybrid material (218 F vs $225 \mathrm{~g}-1$ ). The electrolyte diffusion and electronic conductivity of the activated carbon electrodes were analyzed by EIS. The overall cell resistance (Rs), internal electrode resistance (Rp), as well as equivalent series resistance (ESR), were calculated from the recorded Nyquist plots (Figure 5b) and are listed in Table 3. The presence of the GO-derived graphenic sheets embedded throughout the xerogels together with a more continuous, interconnected nanostructure appears to contribute to electron transport if one considers the difference in the ESR values for K1_T8 (1.50 $\Omega)$ and Glu_K1_T8 $(2,17 \Omega)$ samples. We can also notice that the K4 electrodes, K4_T8 in particular, display the highest ESR values (2.04 and $2.87 \Omega)$. Hence, activation with a 
lower amount of $\mathrm{KOH}$ can be associated to a better electronic conduction within the electrode. Similarly, the analysis of medium-high frequencies (Warburg region) in the Nyquist plots reveals that K1 xerogels also exhibit a lower resistance to electrolyte diffusion compared with their K4 counterparts. Rather than being mostly due to the texture and/or surface chemistry characteristics of the xerogels, which are relatively similar for all the investigated materials, we believe such a behaviour to be mainly governed by their nanostructural features. In fact Glu_K1_T8, which exhibited a loose morphology of micrometer-sized carbon spheres, displayed a much larger resistance to ionic diffusion in the Warburg region as compared to the activated carbon materials that incorporated GO sheets. As discussed above, the K1 xerogels comprise smooth, continuous (i.e., well interconnected) and very thin $(\sim 5-15 \mathrm{~nm})$ carbon walls, whereas the nanostructure of their K4 counterparts is dominated by considerably thicker (40-80 $\mathrm{nm}$ ) as well as frequently broken and partly detached walls (see Figure 1). Therefore, in agreement with the EIS results, we would expect (i) a lower electronic conduction for the carbon materials with broken, partly detached walls (i.e., the K4 xerogels), as this would hamper the movement of charge carriers throughout the electrode, and (ii) a higher resistance to electrolyte diffusion for the carbon materials with thicker walls (again, the K4 xerogels), because it would take longer for the ions to fully occupy the inner porosity of their walls [11]. 


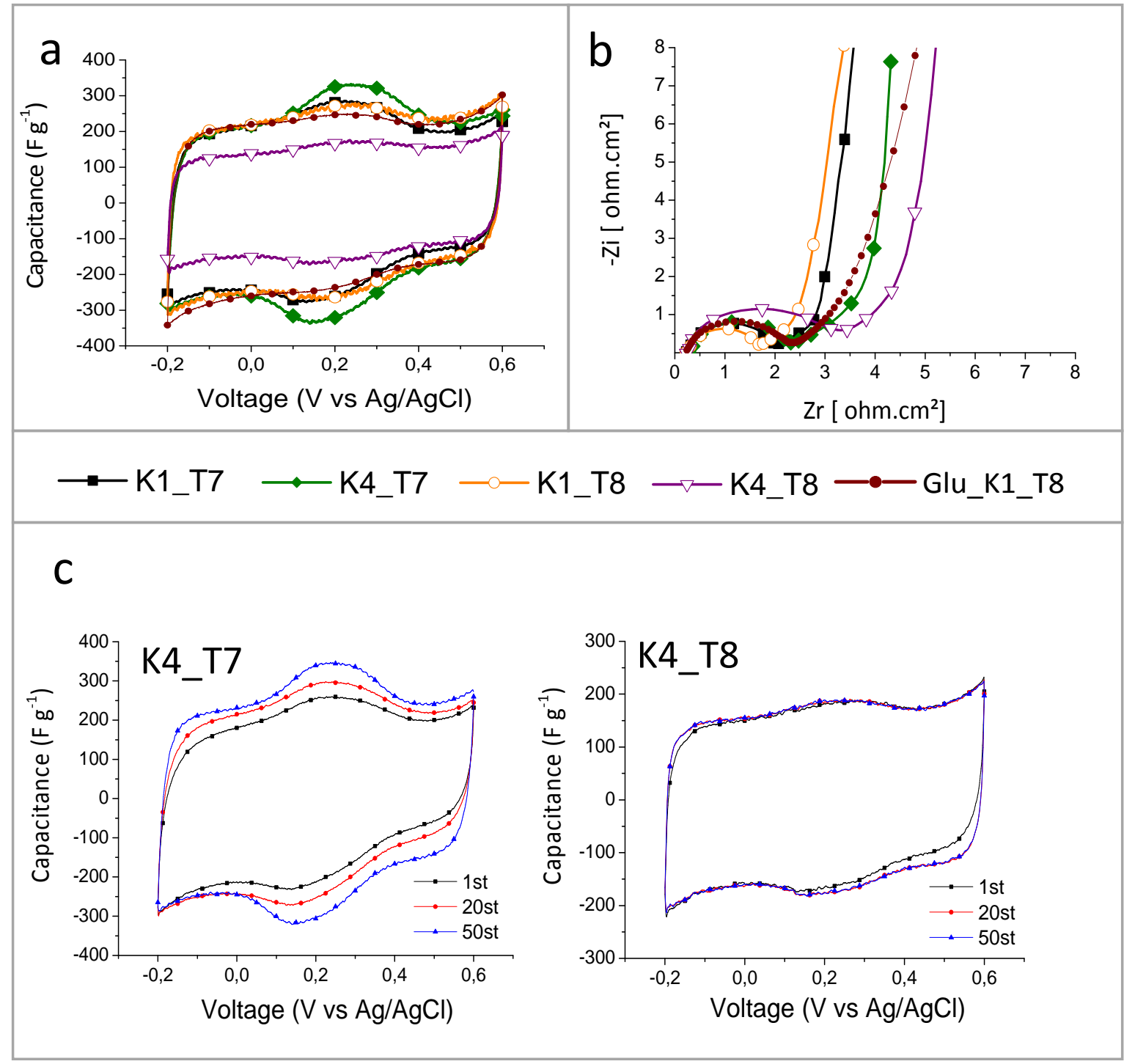

Figure 5. Electrochemistry of the activated carbon xerogels examined in a threeelectrode cell configuration ( $\left.1 \mathrm{M} \mathrm{H}_{2} \mathrm{SO}_{4}\right)$. (a) Cyclic voltammograms recorded at a scan rate of $2 \mathrm{mV} / \mathrm{s}$. (b) Nyquist plots extracted from EIS data. 


\subsection{Supercapacitor performance.}

The performance of the activated xerogels as SC electrodes was tested in a twoelectrode cell in aqueous medium $\left(1 \mathrm{M} \mathrm{H}_{2} \mathrm{SO}_{4}\right)$. The results of the measurements are collected in Figure 6. The generally conductive character of all the prepared xerogels is evidenced by the square shape of their corresponding cyclic voltammograms (Figure 6a). The presence of a broad hump during the cathodic sweep at voltages lower than 0.4 $\mathrm{V}$ suggests the occurrence of some redox processes on the electrode surface [35]. The capacitive behavior of the electrodes was evaluated by galvanostatic CD experiments up to $0.8 \mathrm{~V}$ at a current density of $100 \mathrm{~mA} \mathrm{~g}^{-1}$, as shown in Figure $6 \mathrm{~b}$. All the samples display symmetrical CD curves with a small deviation from linearity, which could be attributed to the faradaic activity. As noticed from Table 3, xerogels activated at $800{ }^{\circ} \mathrm{C}$ present almost identical capacitance values for both the cell configurations (compare three- and two-electrode data for samples Glu_K1_T8, K1_T8 and K4_T8). This is not the case for xerogels activated at $700{ }^{\circ} \mathrm{C}$, which shows a $\sim 10 \%$ decrease in capacitance when tested on the SC device. The dependence of specific capacitance on the current density applied was examined by charging-discharging the electrodes from 100 to 3000 $\mathrm{mA} \mathrm{g}^{-1}$ (Figure 6c). For comparative purposes, an electrode made from a commercial activated carbon (Norit DLC Supra 50) was also tested in the same set-up. Compared with the other electrodes, the performance of both K4_T7 and Supra 50 deteriorates significantly with increasing current density. Moreover, the commercial activated carbon possess a much lower capacitance $\left(153 \mathrm{~F} \mathrm{~g}^{-1}\right.$ at $\left.100 \mathrm{~mA} \mathrm{~g}^{-1}\right)$ than that of the investigated xerogels (except K4_T8), despite its much higher surface area $\left(2090 \mathrm{~m}^{2} \mathrm{~g}^{-}\right.$ $\left.{ }^{1}\right)$. It is also noteworthy that, despite having been activated under the same conditions as those used for the K1_T8 xerogel and exhibiting very similar porous texture, the 
capacitance of Glu_K1_T8 drops dramatically with increasing current density. We attribute this outcome to hindered diffusion of the electrolyte ions into and out of the innermost porosity present in the micrometer-sized spheres that comprise the Glu_K1_T8 sample. By contrast, being made of very thin $(\sim 5-15 \mathrm{~nm})$ and highly accessible porous carbon walls, hindered diffusion is much less of a problem in the case of the K1_T8 xerogel. The relevance of enhanced electrolyte diffusion through very thin pore walls is therefore highlighted by the superior electrochemical behaviour of the K1 xerogels, i.e. the pathway that the electrolyte ions complete within the $\mathrm{K} 1$ xerogels is expected to be particularly short (carbon walls $\sim 5-15 \mathrm{~nm}$ thick), and furthermore, to be assisted by the presence of some mesoporosity (see Table 1). It should be noted that K4_T8 also yields good capacitance retention (Figure $6 \mathrm{c}$ and Table 3), but in such case this could be probably caused by a significant capacitive/negligible pseudocapacitive storage on the electrode (see Figure 5a). The key role played by the nanostructural features of the activated carbon xerogels prepared here towards their electrochemical performance is also made evident by comparison with other materials reported in the literature. Activated xerogels prepared by HTC generally present poor capacitance retention at high current densities, which is an important hurdle when considering their actual implementation as electrodes for supercapacitor devices. For instance, HTC carbons derived from hemicellulose [40], rye straw and cellulose [41] or sucrose [42] suffer from a $50 \%$ reduction of their initial capacitance by increasing the current density from 25 to $1000 \mathrm{~mA} / \mathrm{g}$ in aqueous electrolyte. On the other hand, the capacitance is well known to increase with increasing conductivity of the electrode [6], which should have also contributed to the fact that K1_T8 exhibited the best electrochemical performance: this xerogel not only possesses enhanced ionic diffusion derived from a thin-walled cellular morphology (Figure 1a-c) but also a low electron 
resistance (Table 2). The electrochemical stability of K1_T8 was hence studied by consecutive CD cycles (voltages up to $0.8 \mathrm{~V}$ at $1000 \mathrm{~mA} \mathrm{~g}^{-1}, 10000$ cycles). As noticed from Figure 6d, the good cycling behavior of this xerogel is revealed by high capacitance retention $(\sim 87 \%)$ and an acceptable preservation of the columbic efficiency.
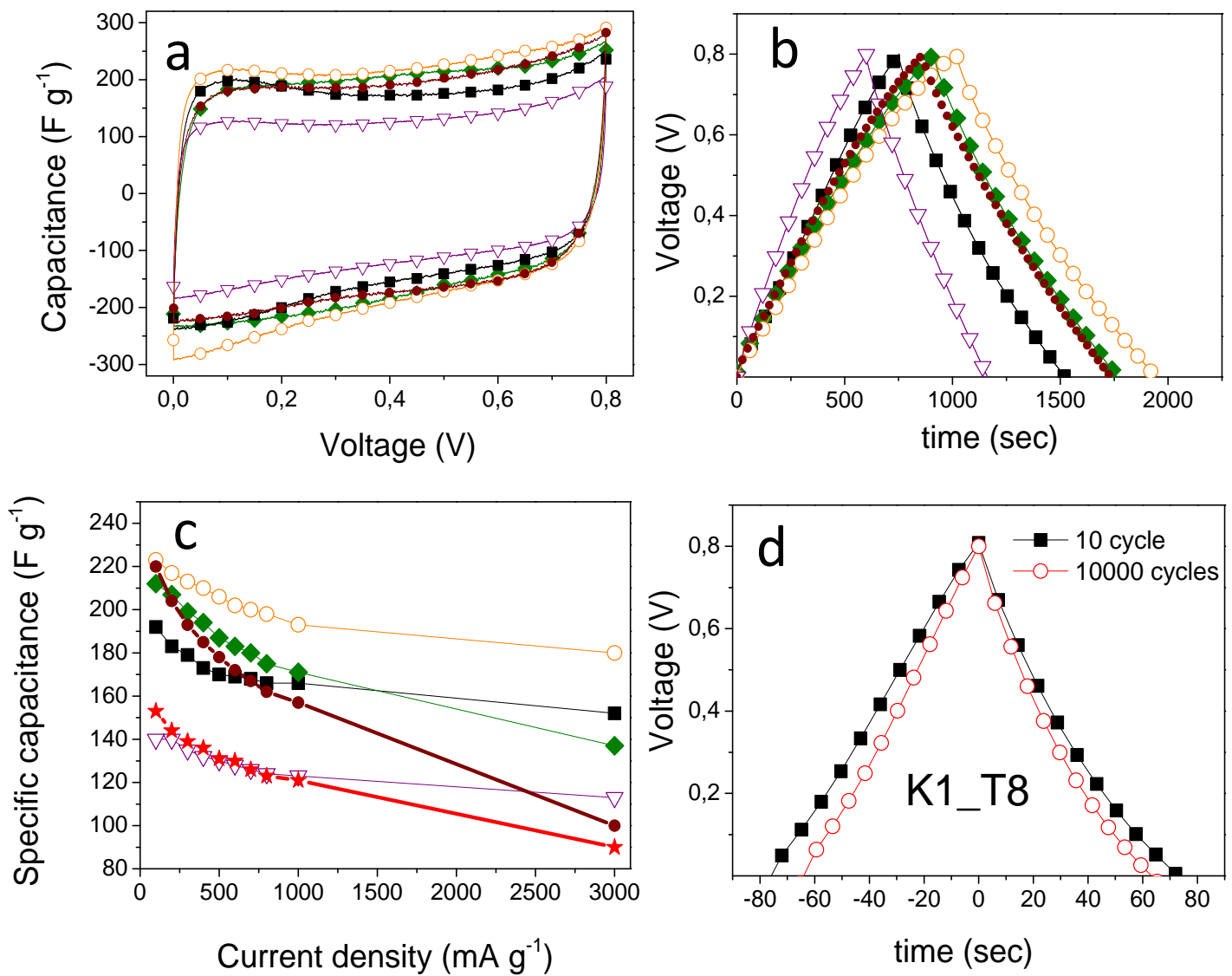

Current density $\left(\mathrm{mA} \mathrm{g}^{-1}\right)$

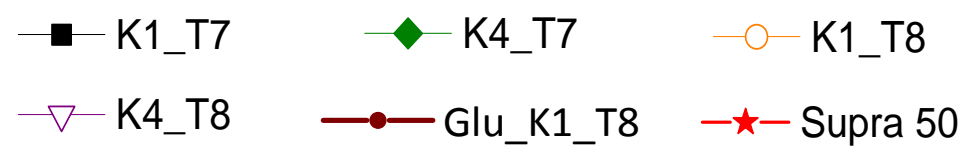

Figure 6. Electrochemical performance of the activated carbon xerogels in aqueous $1 \mathrm{M}$ $\mathrm{H}_{2} \mathrm{SO}_{4}$ under a two-electrode configuration. (a) Cyclic voltammograms at a scan rate of $2 \mathrm{mV} / \mathrm{s}$. (b) Galvanostatic charge-discharge profiles at a current density of $100 \mathrm{~mA} / \mathrm{g}$. (c) Evolution of the specific capacitance with current load ranging from 100 to $3000 \mathrm{~mA} / \mathrm{g}$. (d) Cyclability test for the K1_T8 electrode at $1 \mathrm{~A} / \mathrm{g}$ for 10000 cycles. 
Table 3. Electrochemical parameters for the activated carbon xerogels extracted from measurements with three- and two-electrode configurations.

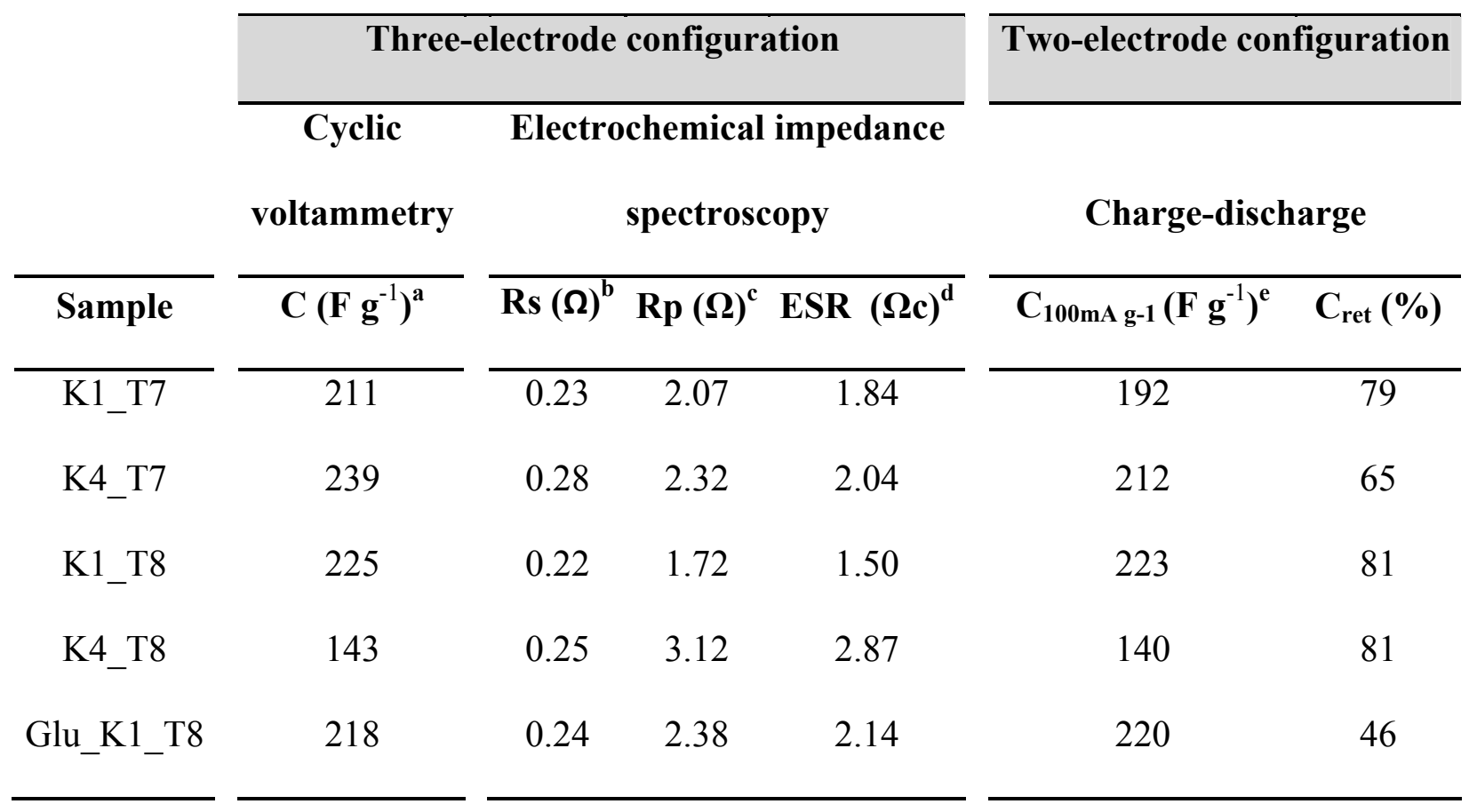

a calculated from Equation 1.

${ }^{\mathrm{b}}$ calculated from the point of intersection with the $x$-axis in the high frequency region.

${ }^{\mathrm{c}}$ calculated from the point of intersection with the $x$-axis from medium frequency region.

${ }^{d}$ diameter of the semicircle at high frequency region $(\mathrm{Rp}-\mathrm{Rs})$.

e calculated from Equation 2. 


\section{Conclusions}

Activated carbon xerogels have been prepared by hydrothermal carbonization of glucose in the presence of graphene oxide nanosheets as morphology-directing agents, followed by chemical activation with $\mathrm{KOH}$. The resulting xerogels exhibit an outstanding electrochemical performance when tested towards supercapacitor electrodes, with values of specific capacitance and capacitance retention outperforming those of a commercial activated carbon commonly studied as supercapacitor electrode and having a significantly more developed porosity than that of the present xerogels. Morphological, structural, textural and chemical characterization of the activated xerogels suggests that their electrochemical behavior is mainly dictated by their peculiar nanostructure. Specifically, the use of a lower amount of $\mathrm{KOH}$ during the activation step affords xerogels with a well-developed cellular morphology comprising smooth, continuous (well interconnected) and very thin porous carbon walls, which favors both the electronic conduction and ionic diffusion in the corresponding electrodes. By contrast, the electrochemical performance is impaired when using a higher amount of $\mathrm{KOH}$, as this leads to activated xerogels with much thicker, broken and partly detached carbon walls. These specific nanostructural features originate from the combined effect of $\mathrm{GO}$ as a morphology directing agent and $\mathrm{KOH}$ as an activating agent. Overall, the present results suggest these activated carbon xerogels to be good candidates for capacitive energy storage, especially at high current densities.

\section{Acknowledgments}

This work was financed by QREN, ON2, FCT and FEDER (Project NORTE-07-0124FEDER-000015 and NORTE-07-0162-FEDER-000050), and co-financed by FCT and 
FEDER through COMPETE 2020 (Project UID/EQU/50020/2013 - POCI-01-0145-

FEDER-006984). Partial funding of this work by the Spanish MINECO and the European Regional Development Fund (projects MAT2015-69844-R and MAT201234011 ) is also gratefully acknowledged.

\section{References}

[1] A. Taheri Najafabadi, Renew, Emerging applications of graphene and its derivatives in carbon capture and conversion: Current status and future prospects, Sust. Energ. Rev, 41 (2015) 1515-1545.

[2] E. Frackowiak, Q. Abbas, F. Beguin, Carbon/carbon supercapacitors, J. Energy Chem, 22 (2013) 226-240.

[3] M. Winter, R.J. Brodd, What Are Batteries, Fuel Cells, and Supercapacitors?, Chem. Rev., 104 (2004) 4245-4270.

[4] G. Wang, L. Zhang, J. Zhang, A review of electrode materials for electrochemical supercapacitors, Chem. Soc. Rev., 41 (2012) 797-828.

[5] B.E. Conway, V. Birss, J. Wojtowicz, The role and utilization of pseudocapacitance for energy storage by supercapacitors, J. Power Sources, 66 (1997) 1-14.

[6] M. Seredych, M. Koscinski, M. Sliwinska-Bartkowiak, T.J. Bandosz, Active pore space utilization in nanoporous carbon-based supercapacitors: Effects of conductivity and pore accessibility, J. Power Sources, 220 (2012) 243-252.

[7] M. Enterría, A. Castro-Muñiz, F. Suárez-García, A. Martínez-Alonso, J.M.D. Tascón, T. Kyotani, Effects of mesostructure order on electrochemical performance of hierarchical micro-mesoporous carbons, J. Mater. Chem. A, 2 (2014) 12023-12030. 
[8] G.A. Ferrero, M. Sevilla, A.B. Fuertes, Mesoporous carbons synthesized by direct carbonization of citrate salts for use as high-performance capacitors, Carbon, 88 (2015) $239-251$.

[9] T. Matsui, S. Tanaka, Correlation between the capacitor performance and pore structure of ordered mesoporous carbons.Y. Miyake, Adv. Powder Technol., 24 (2013) 737-742.

[10] J. Sánchez-González, F. Stoeckli, T.A. Centeno, The role of the electric conductivity of carbons in the electrochemical capacitor performance, J. Electroanal. Chem., 657 (2011) 176-180.

[11] X. Zheng, J. Luo, W. Lv, D.-W. Wang, Q.-H. Yang, Two-Dimensional Porous Carbon: Synthesis and Ion-Transport Properties, Adv. Mater., 27 (2015) 5388-5395.

[12] S. Yun, S.O. Kang, S. Park, H.S. Park, CO2-activated, hierarchical trimodal porous graphene frameworks for ultrahigh and ultrafast capacitive behavior, Nanoscale, 6 (2014) 5296-5302.

[13] R.W. Pekala, Organic aerogels from the polycondensation of resorcinol with formaldehyde, J Mater Sci, 24 (1989) 3221-3227.

[14] J.L. Figueiredo, Functionalization of porous carbons for catalytic applications, J. Mater. Chem. A, 1 (2013) 9351-9364.

[15] R.J. White, N. Brun, V.L. Budarin, J.H. Clark, M.-M. Titirici, Always Look on the "Light" Side of Life: Sustainable Carbon Aerogels, ChemSusChem, 7 (2014) 670-689.

[16] F.J. Martín-Jimeno, F. Suárez-García, J.I. Paredes, A. Martínez-Alonso, J.M.D. Tascón, Activated carbon xerogels with a cellular morphology derived from hydrothermally carbonized glucose-graphene oxide hybrids and their performance towards CO2 and dye adsorption, Carbon, 81 (2015) 137-147. 
[17] L. Liu, J. Yang, Q. Meng, Graphene cross-linked phenol-formaldehyde hybrid organic and carbon xerogel during ambient pressure drying, J. Sol-Gel Sci. Technol., 66 (2013) 1-5.

[18] M. Sevilla, A.B. Fuertes, Chemical and structural properties of carbonaceous products obtained by hydrothermal carbonization of saccharides, Chem.- Eur. J., 15 (2009) 4195-4203.

[19] J. Yan, Q. Wang, C. Lin, T. Wei, Z. Fan, Interconnected Frameworks with a Sandwiched Porous Carbon Layer/Graphene Hybrids for Supercapacitors with High Gravimetric and Volumetric Performances, Adv. Energy. Mater., 13 (2014) 1400500.

[20] H.J. Peng, J.Q. Huang, M.Q. Zhao, Q. Zhang, X.B. Cheng, X.Y. Liu, W. Z. Qian, F. Wei, Nanoarchitectured Graphene/CNT@Porous Carbon with Extraordinary Electrical Conductivity and Interconnected Micro/Mesopores for Lithium-Sulfur Batteries, Adv. Funct. Mater., 19 (2014) 2772-2781.

[21] X. Yang, L. Zhang, F. Zhang, Y. Huang, Y. Chen, Sulfur-Infiltrated GrapheneBased Layered Porous Carbon Cathodes for High-Performance Lithium-Sulfur Batteries, ACS Nano., 8 (2014) 5208-5215.

[22] J.I. Paredes, S. Villar-Rodil, P. Solís-Fernández, A. Martínez-Alonso, J.M.D. Tascón, Atomic Force and Scanning Tunneling Microscopy Imaging of Graphene Nanosheets Derived from Graphite Oxide, Langmuir, 25 (2009) 5957-5968.

[23] Adsorption by Powders \& Porous Solids. Principles, Methodology and Applications, in: F. Rouquerol, J. Rouquerol, K.W.S. Sing (Ed) Academic Press New York, 1999. 
[24] M. Enterría, M.F.R. Pereira, J.I. Martins, J.L. Figueiredo, Hydrothermal functionalization of ordered mesoporous carbons: The effect of boron on supercapacitor performance, Carbon, 95 (2015) 72-83.

[25] A.C. Ferrari, J. Robertson, Interpretation of Raman spectra of disordered and amorphous carbon, Phys. Rev. B, 61 (2000) 14095-14107.

[26] M.A. Pimenta, G. Dresselhaus, M.S. Dresselhaus, L.G. Cancado, A. Jorio, R. Saito, Studying disorder in graphite-based systems by Raman spectroscopy, Phys. Chem. Chem. Phys., 9 (2007) 1276-1290.

[27] R. Rozada, J.I. Paredes, S. Villar-Rodil, A. Martínez-Alonso, J.M.D. Tascón, Towards full repair of defects in reduced graphene oxide films by two-step graphitization, Nano Res., 6 (2013) 216-233.

[28] L.M. Pastrana-Martínez, S. Morales-Torres, V. Likodimos, P. Falaras, J.L. Figueiredo, J.L. Faria, A.M.T. Silva, Role of oxygen functionalities on the synthesis of photocatalytically active graphene-TiO2 composites, Appl. Catal. B-Environ., 158-159 (2014) 329-340.

[29] G. Srinivas, J. Burress, T. Yildirim, Graphene oxide derived carbons (GODCs): synthesis and gas adsorption properties, Energy Environ. Sci., 5 (2012 6453-6459.

[30] Linares-Solano.A, Lozano-Castelló.D, Lillo-Ródenas.M.A, D. Cazorla-Amorós, Carbon activation by alkaline hydroxides: Preparation and reactions, porosity and performance, in: LR. Radovic (Ed), Chemistry and Physics of Carbon, Boca Raton: CRC Press; 2007 pp. 1-62.

[31] K. Cao, Y. Tian, Y. Zhang, X. Yang, C. Bai, Y. Luo et al., Strategy and mechanism for controlling the direction of defect evolution in graphene: Preparation of high quality defect healed and hierarchically porous graphene, Nanoscale, 6 (2014) 13518-13526. 
[32] Y. Zhu, S. Murali, M.D. Stoller, K.J. Ganesh, W. Cai, P.J. Ferreira et al., CarbonBased Supercapacitors Produced by Activation of Graphene, Science, 332 (2011) 15371541.

[33] J.L. Figueiredo, M.F.R. Pereira, M.M.A. Freitas, J.J.M. Órfão, Modification of the surface chemistry of activated carbons, Carbon, 37 (1999) 1379-1389.

[34] D. Hulicova-Jurcakova, M. Seredych, G.Q. Lu, T.J. Bandosz, Combined Effect of Nitrogen- and Oxygen-Containing Functional Groups of Microporous Activated Carbon on its Electrochemical Performance in Supercapacitors, Adv. Funct. Mater., 19 (2009) 438-447.

[35] E. Raymundo-Piñero, F. Leroux, F. Béguin, A high-performance carbon for supercapacitors obtained by carbonization of a seaweed biopolymer, Adv. Mater, 18 (2006) 1877-1882.

[36] M.A. Montes-Morán, D. Suárez, J.A. Menéndez, E. Fuente, On the nature of basic sites on carbon surfaces: an overview, Carbon, 42 (2004) 1219-1225.

[37] H. Itoi, H. Nishihara, T. Ishii, K. Nueangnoraj, R. Berenguer-Betrián, T. Kyotani, Pseudocapacitance in Quinone-Functionalized Zeolite-Templated Carbon, Bull. Chem. Soc. Jpn., 87 (2014) 250-257.

[38] K. Nueangnoraj, R. Ruiz-Rosas, H. Nishihara, S. Shiraishi, E. Morallón, D. Cazorla-Amorós et al., Carbon-carbon asymmetric aqueous capacitor by pseudocapacitive positive and stable negative electrodes, Carbon, 67 (2014) 792-794.

[39] N.Katsuhiko, Electrochemical supercapacitors and hybrid systems, in: R.J..Brodd (Ed), Batteries for Sustainability, Springer Ed, 2013 pp 93-115.

[40] C. Falco, J.M. Sieben, N. Brun, M. Sevilla, T. Van Der Mauelen, E. Morallón, D. Cazorla-Amorós, M. M. Titirici, Hydrothermal carbons from hemicellulose-derived 
aqueous hydrolysis products as electrode materials for supercapacitors, ChemSusChem., $6(2013) 374-382$.

[41] D. Salinas-Torres, D. Lozano-Castello, M.M. Titirici, L. Zhao, L. Yu, E. Morallón, D. Cazorla-Amorós, Electrochemical behaviour of activated carbons obtained via hydrothermal carbonization, J. Mater. Chem. A. 3 (2015) 15558-15567.

[42] L. Mao, Y. Zhang, Y. Hu, K.H. Ho, Q. Ke, H. Liu, et al. Activation of sucrosederived carbon spheres for high-performance supercapacitor electrodes. RSC Adv., 5 (2015) 9307-9313. 